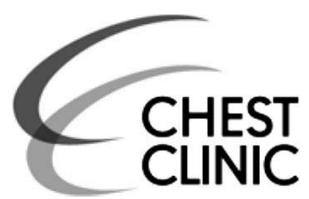

Medicine, Division of

Respiratory, Allergy and Critical

Care Medicine, Korea University Guro Hospital, Korea University College of Medicine, Seoul Guro-gu, Republic of Korea

\section{Correspondence to}

Dr Jae Jeong Shim, Department of Internal Medicine, Division of Respiratory and Critical Care Medicine, Korea University Guro Hospital, Korea University College of Medicine, 148 Gurodong-ro, Seoul, Guro-gu 08308, Republic of Korea; jaejshim@kumc.or.kr

$J C$ and JJS contributed equally.

Received 15 May 2017

Revised 19 July 2017

Accepted 24 July 2017

Published Online First

11 August 2017

\title{
Rare adult presentation of fixed airways obstruction: remember aortic arch abnormalities
}

Juwhan Choi, Kyung Hoon Min, Sung Yong Lee, Kyung Ho Kang, Jae Jeong Shim
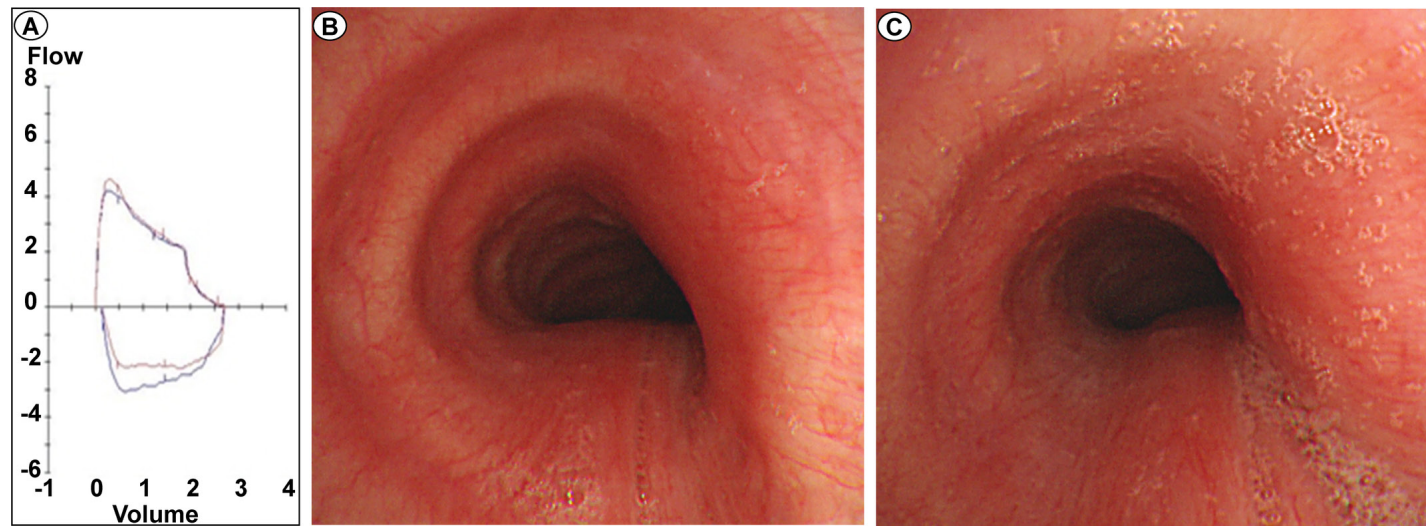

Figure 1 (A) Pulmonary function test shows a fixed obstruction pattern. (B) Functional obstruction on lower trachea during full inspiration on bronchoscopy imaging (60\%-70\% obstruction). (C) Functional obstruction on lower trachea during full expiration on bronchoscopy imaging (70\%-80\% obstruction).
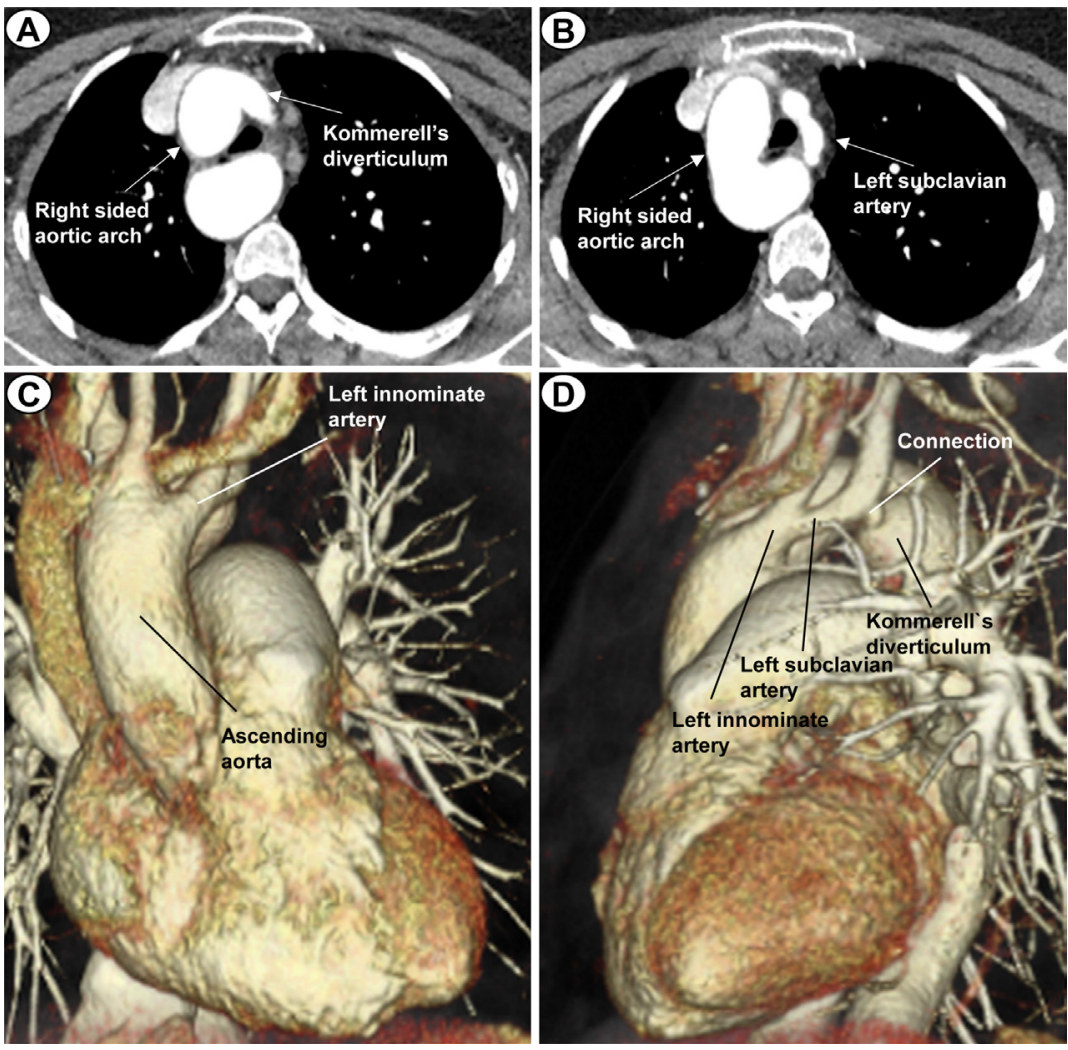

To cite: Choi J, Min KH, Lee SY, et al. Thorax 2018;73:298-299.

Figure 2 (A,B) CT scan shows a vascular ring formed by connecting Kommerell's diverticulum and a left subclavian artery. $(C, D)$ three dimensional reconstruction image by $C T$ aortography shows a left innominate artery from the ascending aorta and connection between Kommerell's diverticulum and left subclavian artery. 
A 47-year-old woman with a history of chronic cough presented with dyspnoea. She had no history of smoking, tuberculosis and cardiovascular disease. Physical examination revealed wheezing in both lungs. We started maintenance and reliever therapy for suggested bronchial asthma. However, symptoms did not improve, and she was hospitalised repeatedly. Chest X-ray showed a right-sided aortic arch. In the pulmonary function test, a fixed obstruction pattern was observed, and a bronchodilator response was not seen (figure 1A). On bronchoscopy, functional obstruction with extrinsic compression at the level of the lower trachea was shown (figure 1B,C). Chest CT and CT aortography showed a right-sided aortic arch and a left subclavian artery (LSA) with a Kommerell's diverticulum. The LSA originated from a left innominate artery, connected with the diverticulum and formed a vascular ring (figure 2A-D) that caused fixed extrinsic compression on the lower trachea.

Kommerell's diverticulum with a right-sided aortic arch is a rare congenital aortic arch abnormality that is mainly found in infancy. ${ }^{12}$ The main symptoms are dysphagia, recurrent airway infection and dyspnoea. ${ }^{3}$ Sometimes, dyspnoea is accompanied by wheezing, which makes it difficult to differentiate from asthma. ${ }^{4}$ When the aortic arch appears on the chest
$\mathrm{X}$-ray, it is often overlooked. Although not common, clinicians need to consider that dyspnoea can be caused by aortic arch abnormality.

Contributors Study concept and design: JC and JJS. Acquisition, analysis or interpretation of data, critical revision of the manuscript for important intellectual content and study supervision: all authors. Drafting of the manuscript : JC and JJS.

Competing interests None declared.

Patient consent Obtained.

Provenance and peer review Not commissioned; externally peer reviewed.

(c) Article author(s) (or their employer(s) unless otherwise stated in the text of the article) 2018. All rights reserved. No commercial use is permitted unless otherwise expressly granted.

\section{REFERENCES}

1 Bhatt TC, Muralidharan CG, Singh G, et al. Kommerell's diverticulum: A rare aortic arch anomaly. Med J Armed Forces India 2016;72:S80-3.

2 Hanneman K, Newman B, Chan F. Congenital variants and anomalies of the Aortic Arch. Radiographics 2017;37:32-51.

3 Domènech $A B$, López J, Rodríguez $P$, et al. (Vascular rings, our experience with 18 cases). Cir Pediatr 2014;27:110-6.

4 Lone GN, Rathore SS, Malik JA, et al. Double aortic arch masquerading as bronchial asthma for five decades. Asian Cardiovasc Thorac Ann 2012;20:338-40. 